\title{
EFFECTS OF INDUGING LUMINANCE AND AREA UPON THE APPARENT BRIGHTNESS OF TEST FIELD ${ }^{1}$
}

\author{
SHUKO TORII ${ }^{2}$ AND YASUKO UEMURA
}

University of Tokyo

\begin{abstract}
The present study was designed to examine whether the apparent brightness of the test field was affected by varying the inducing field luminance and area. Binocular matching method was used. The apparent brightness of the test field was measured by the method of adjustment. The test field was disc-shaped and, in Experiment I and II, was surrounded by a contiguous annular inducing field of different areas. Effects of inducing luminance and area upon the test brightness were studied in Experiment I. In Experiment II, the test brightness surrounded by the inducing field of equal luminance was measured. It was also examined whether the apparent brightness of a field could be changed by varying its area in Experiment III.
\end{abstract}

The apparent brightness of a luminous stimulus (the test field) presented to the foveal region of the retina may be affected by another stimulus (the inducing field) presented in the neighborhood of the first one. This effect has been called "simultaneous brightness induction". Induction may be observed in the change of the apparent brightness of the test field, either as an enhancement or a depression of the brightness. The depression has been called "simultaneous brightness contrast".

Hess and Pretori (1894) investigated the induction as a function of inducing- and test-field luminances for a $1^{\circ} \times 1^{\circ}$ square test field surrounded by a $10^{\circ} \times 10^{\circ}$ inducing field. They used a monocular matching method and determined that the apparent brightness of the test field decreased directly proportional to the luminance of the inducing field. In their experiments, however, the comparison field

1 The authors are indebted to Dr. Y. Tanaka of University of Tokyo for his valuable suggestions and to Dr. H. Leibowitz of Pennsylvania State University for his criticism concerning the manuscript. They also wish to thank Mr. T. Murakami of Narumi Shokai Co. Ltc. for preparing the apparatus used here.

${ }^{2}$ Now at Tokyo University of Agriculture and Technology. was also surrounded by a $10^{\circ} \times 10^{\circ}$ inducing field. Thus, altogether, the stimulus pattern consisted of four fields of different luminance. As has been pointed out by Diamond (1953), an unambiguous interpretation of Hess and Pretori's results is difficult because of the many possible interactions among the four fields.

In order to avoid the difficulties inherent in Hess and Pretori's investigation, the binocular matching method has been used in recent investigations (Diamond, 1953 ; Fry and Alpern, 1953; Leibowitz et al., 1953; Heinemann, 1955). With this method, the inducing- and test-fields are presented to one eye, and the matching field (usually of the same shape and size as the test field) is presented to the other eye. These stimuli are arranged as to fall upon noncorresponding points, so that interaction between the two eyes is considered as negligible.

Fry and Alpern (1953), Diamond (1953), and Heinemann (1955) investigated induction as a function of inducing- and testfield luminances by using this binocular matching method. In Fry and Alpern's investigation, the test field was a $2.5^{\circ} \times .5^{\circ}$ rectangle centered between two inducing fields of the same size and shape. In Diamond's investigation the inducing- and 
test-fields were adjacent squares, each subtending 33'. These investigations agree in showing little effect in the apparent brightness of the test field by inducingfield luminances less than the test-field luminance, and a depression of the testfield brightness by inducing-field luminances greater than the test-field luminance.

Heinemann investigated the effects of varied luminances of the inducing- and testfields for a disc-shaped test field (subtending an angle of $28^{\prime}$ ) completely surrounded by a contiguous annular inducing field (subtending an angle of 55'). He found that when the luminance of the inducing field was much lower than the test-field, slight enhancement of the test field occurred. When the luminance of the inducing field was almost equal to or greater than that of the test field, depression of the test field occurred.

Since the above cited investigators could not find the initial enhancement effect, Heinemann's results differ from those of the former. This disagreement may be attributable to the differences in inducingand test-fields between Heinemann's and the former ones. It should be noted that Heinemann's inducing area was not only much larger than the test area, but also surrounded the test area. According to Heinemann, MacLeod (1947) also found an enhancement effect similar to Heinemann's for a disc-shaped test field surrounded by an annulus of graded luminance.

On the other hand, Diamond (1955) performed two experiments, concerning the effect of the inducing area upon the apparent brightness of the test field. In both experiments, an identical stimulus, a rectangle of $33^{\prime} \times 16.5^{\prime}$ was used as the test field. However, the inducing field differed in its vertical extent from zero to $33^{\prime}$. The results of both experiments showed that the apparent brightness of the test field decreased as the area of the inducing field increased only under the condition in which the luminance of the inducing field was equal to or greater than that of the test field. Here also, only the depression effect was exhibited.

The present experiments were planned to investigate the effects of different luminosity of a contiguous annular inducing field upon the apparent brightness of a discshaped test field, using a binouclar matching method. At the same time, it was also examined, by varying the area of the inducing field, whether differences of inducing-field area are related to enhancement or depression effects.

\section{General Method}

\section{Apparatus}

The basic stimulus arrangement consisted of three stimuli ; the "test field (TF)", the "inducing field (IF)", and the "matching field (MF)". In order to use the binocular matching method, TF and IF were presented to the left eye of the subject $(S)$, and MF was presented to the right eye. TF and MF were evenly illuminated disks each diameter of which was $36^{\prime}$. If was an evenly illuminated ring whose outer diameter was varied. TF was surrounded by IF but both were separated by a very thin black circular line.

The stimulus pattern is shown in Fig. 1. Fig. 1 (a) presents the monocular views as seen by $S$. Pattern $\mathrm{L}$ is presented to the left eye against a dark background. It consists of $T F$, IF, and the fixation point $F_{1} . \quad S$ fixates $F_{1}$ with the left eye in the course of the experiment. Pattern $\mathrm{R}$ is presented to the right eye; it consists of MF and the fixation point $\mathrm{F}_{2}$. $S$ fixates $F_{2}$ with the right eye during the experiment. The fixation points $F_{1}$ and $F_{2}$ are red circles each subtending an angle of $18^{\prime} . \quad F_{1}$ is located about $1^{2} 24^{\prime}$ to the upper right of the center of TF, and $F_{1}$ is located about $1^{\circ} 24^{\prime}$ to the upper left of the center of MF.

$S$ is instructed to try to fuse the fixation points fixated by the left and right eyes so that when fusion occurs only one fixation point $F$ is seen against a uniform dark background as is shown in Fig. 1 (b). Therefore, TF and MF held constant positions relative to each other through the experiment.

$\mathrm{TF}, \mathrm{IF}, \mathrm{MF}, \mathrm{F}_{1}$, and $\mathrm{F}_{2}$ were presented to $S$ 
through five independent optical paths (Path 1, Path 2, Path 3, Path 4, and Path 5, respectively). Fig. 2 is a schematic diagram of the optical system used in the experiment. $\mathrm{S}_{1}, \mathrm{~S}_{2}$, and $S_{3}$ are the sources of light, for $T F, I F$, and MF, respectively. They are $30 \mathrm{~W}$ tungstenflament projection lamps (color temperature: $3150 \pm 50^{\circ} \mathrm{K}$ ) each of which is housed in a metal box.

TF is presented through Path 1: The light from $S_{1}$, diffused by opal glass $\left(\mathrm{OG}_{1}\right)$, passes through the circular optical wedge $\left(O W_{1}\right)$ and becomes parallel through doublet lens (collimating lens) $\left(\mathrm{L}_{1}\right)$. Then it passes through the neutral density filter (ND fiter) $\left(\mathrm{NDF}_{1}\right)$, the stainless steel mirror (SSM) with an opening,

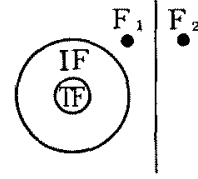

L

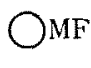

$\mathrm{R}$

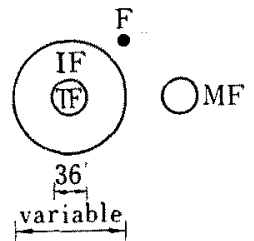

(b)

Fro. 1. Stimulus pattern used in Exp. I and Exp. II.

(a) Left and right monocular views of the test field (TF), the inducing field (IF), and the matching field (MF) with fixation points $F_{\perp}$ and $F_{2}$.

(b) Binocular views with fixation points fused into one point $F$.

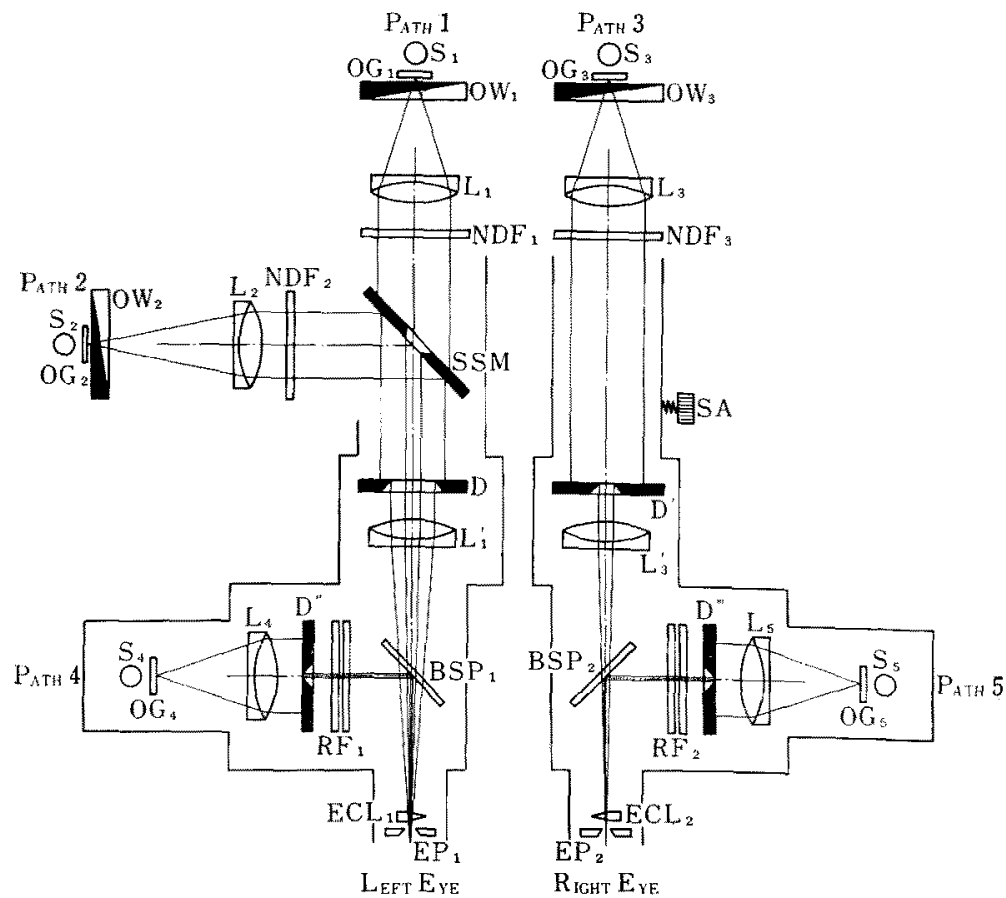

Fig. 2. Diagram of the optical system used in the experiments. 
the size and shape of which determine those of TF seen by $S$. Then it passes through a circular opening of the diaphragm (D), and is focused by an achromatic lens $\left(\mathrm{L}_{1}^{\prime}\right)$. Then the light passes through the beam splitter $\left(\mathrm{BSP}_{1}\right)$, the eccentrically mounted lens $\left(\mathrm{ECL}_{1}\right)$ whose focal length is equal to that of $L_{1}^{\prime}$, and finally a $2 \mathrm{~mm}$ artificial pupil (eye piece, $E P_{1}$ ), and then it enters $S$ 's left eye.

IF is presented through Path 2: The light from $S_{2}$, diffused by opal glass $\left(O G_{2}\right)$, passes through the circular optical wedge $\left(O W_{2}\right)$ and is collimated by lens $\left(\mathrm{L}_{2}\right)$. After passing $\mathrm{ND}$ filter $\left(\mathrm{NDF}_{2}\right)$, it is reflected by the front surface mirror towards the circular opening of the diaphragm (D) and the achromatic lens $\left(\mathrm{L}_{1}{ }^{\prime}\right)$, which brings the light to a focus. The size and shape of IF seen by $S$ are determined by those of an opening in D. The size of IF may be varied by changing the diaphragm of a given size for another one of different size. The shape of IF is always ring-like. The pathway of the light from $\mathrm{L}_{1}^{\prime}$ to $S^{\prime}$ 's left eye is similar to that of Path 1.

Path 3 for presenting MF is similar to Path 1, having labeled elements of comparable function. Differences between them are: (a) Path 3 contains no stainless steel mirror as SSM in Path 1, (b) the size and shape of MF seen by $S$ are determined by the characteristics of a circular opening in the diaphragm (D'). This optical path, Path 3, can be adjusted horizontally by a screw arrangement (SA) for interpupillary distance.

Fixation points, $F_{1}$ and $F_{2}$, are presented to $S$ along two independent optical paths, Path 4 and Path 5, as are shown in Fig. 2. $S_{4}$ and $S_{5}$ are the sources of light for $F_{1}$ and $F_{2}$, respectively. They are both $12 \mathrm{~W}$ tungsten-filament projection lamps each of which is housed in a metal box. Each light, diffused by the respective opal glass $\left(\mathrm{OG}_{4}\right.$ and $\left.O \mathrm{OG}_{5}\right)$, is made parallel by respective doublet lenses $\left(\mathrm{L}_{4}\right.$ and $\left.\mathrm{L}_{5}\right)$. Then they pass successively through its respective pin hole at $\mathrm{D}^{\prime \prime}$ and $\mathrm{D}^{\prime \prime \prime}$, the size of which determines the size of the fixation point, and its respective red filter $\left(R F_{1}\right.$ and $\left.R F_{2}\right)$. They are reflected by its respective beam splitter $\left(\mathrm{BSP}_{1}\right.$ and $\mathrm{BSP}_{2}$ ) towards its respective $\mathrm{ECL}$, which brings each light to a focus. Finally they pass through the respective artificial pupils and enter $S$ 's eyes.

In order to aid $S$ in attaining fusion of the fixation points, the eccentrically mounted lenses, $\mathrm{ECL}_{1}$ and $\mathrm{ECI}_{2}$ are placed (in each eye piece) in such a manner that by rotating both eye pieces $S$ can optically shift both left and right patterns perpendicular to the optical axis.

The luminance of the stimulus patterns could be changed continuously by controlling the combination of $\mathrm{ND}$ filters $\mathrm{NDF}_{1}, \mathrm{NDF}_{2}$, and $\mathrm{NDF}_{3}$ in Fig. 2) of fixed densities and the movable circular optical wedges $\left(O W_{1}, O W_{2}\right.$, and $O W_{3}$ in Fig. 2). The luminances of TF and IF were fixed by using ND filters and optical wedges under each experimental condition while that of MF was varied continuously by optical wedge. On the other hand, the luminance of each fixation point was kept constant through all experimental conditions.

Prior to the experiment, the maximum luminance $(\mathrm{mL})$ of $\mathrm{TF}, \mathrm{IF}$, and $\mathrm{MF}$ were determined by a Macbeth illuminometer. The maximum available test-field luminance was $1.9 \log \mathrm{mL}$. This was also the maximum available luminance of the inducing field and the matching field. The densities of the ND filters and densities of the optical wedge were calibrated photometrically. The luminances of TF and IF in various positions of the wedge's density-scale were also determined by using a Macbeth illuminometer.

\section{Procedure}

The present experiments consist of Experiment I, II, and III. In each experiment, the apparent brightness of the test field was measured by adjusting the matching-field luminance. Four luminance levels of the test field used were as follows: $-0.5,0,0.5$, and $1.0 \mathrm{log}$ $\mathrm{mL}$. Various inducing-luminances and areas used in Experiment I and II, and various testfield areas in Experiment III, will be described in detail later.

The method of adjustment was used. TF was kept constant at a given luminance. The experimenter $(E)$, who stood outside of the light-tight cubicle, slowly and evenly varied the luminance of MF by moving the circular 
optical wedge in aco unter-balanced order of ascending and descending series. As the $E$ slowly increased (decreased) the luminance of $\mathrm{MF}$, the $S$ was instructed to inform the $E$ when MF appeared equal to that of TF. The average of eight such judgments, four of ascending series and four of descending series, was taken as a measure of the test luminance at which both TF and MF were equal in brightness. Prior to these eight judgments, two warm-up matches were done.

$S$ sat in a light-tight cubicle into which were extended the eye pieces of the apparatus and through which the $S$ was able to view the stimulus patterns. His head was fixed by a chin-rest. The $S$ was requested to adjust the artificial pupils in order to fuse the fixation points. The $S$ then viewed an evenly illuminated circle whose diameter was $2^{\circ}$, and whose luminance was $1.9 \log \mathrm{mL}$. Thus, his both eyes light adapted to the illuminated fields with the same size and luminance. This lasted for $7 \mathrm{~min}$, after which $S$ was dark adapted for $15 \mathrm{~min}$.

After adaptation, the control session began by making ten (four ascending and four descending with two warm-up) mutches without IF. During this period, the $S$ was required to stare at the fixation point. This was followed by 2 min of dark adaptation, after which IF was introduced at the lowest level. Throughout the experimental session the inducing- and testfields were presented continuously. The $S$ then was required to make two warm-up and eight more matches, staring at the fixation point. This procedure was repeated for a series of progressively higher luminance values of IF. The average of the eight matches, made without IF, was taken as a measure of the control session.

Subjects

Two subjects, ST (male) and YU (female), were employed. They had normal vision, and were well-experienced in the matching of brightness between illuminated fields presented separately to the left and the right eye. Each served as $S$ in all experiments to be described.

\section{EXPERIMENT I}

Method

In Experiment I, the luminance of the matching field was adjusted to equal the apparent brightness of the test field for each of four different levels of test-field luminance surrounded by each of the three different areas of the inducing field. Six different levels of the inducing luminance for each level of the test luminance are shown in the following table.

TABLE 1

\begin{tabular}{|c|c|}
\hline $\begin{array}{l}\text { Lu- } \\
\text { minance } \\
\text { of TF } \\
(\log \mathrm{mL})\end{array}$ & $\begin{array}{l}\text { Luminance of IF } \\
\qquad(\log \mathrm{mL})\end{array}$ \\
\hline 1.0 & $0, \quad 0.5, \quad 0.8, \quad 1.2$ \\
\hline 0.5 & $\begin{array}{lllll}-1.0,-0.5, & 0, & 0.2, & 0.4, & 0.7\end{array}$ \\
\hline 0 & $-1.0,-0.7,-0.5,-0.3,-0.1, \quad 0.2$ \\
\hline-0.5 & $-1.0,-0.8,-0.7,-0.6,-0.4,-0.3$ \\
\hline
\end{tabular}

The three areas of the inducing field employed were $0.8^{\circ}, 1.0^{\circ}$, and $2.0^{\circ}$ of arc in diameter. An experimental session for one day was designed to explore six levels of the inducingfield luminance for a fixed luminance of the test field and a fixed area of the inducing field. The effects of area were explored on succeeding days in balanced order for two subjects, keeping * the level of the test-field luminance the same as the preceding day. After exploring three inducing-field areas, the level of the test-field luminance was changed to a new one. The same procedure was repeated at a new level of test-field luminance. The order of changing the level of the test-field luminance differed for two subjects.

Results

The individual results for the two $S$ s are presented in Table 2 in which $B t$ is the luminance of TF. $B m$ indicates the luminance of $\mathrm{MF}$, and $B i$ is the luminance of IF. In Fig. $3 \mathrm{~A}$ and $3 \mathrm{~B}, \log B m$ is plotted against $\log B i$. Fig. $3 \mathrm{~A}$ indicates the results of subject $\mathrm{YU}$ and Fig. 3B subject ST. Fig. 3A and $3 \mathrm{~B}$ are divided into (a), (b), and (c), according to the difference of the area of IF. Four different curves are 
shown in each of Fig. $3 \mathrm{~A}$ and $3 \mathrm{~B}$, for the four luminance levels of TF. Curves were fitted by inspection.

These curves show that the apparrent brightness of $\mathrm{TF}$ increases somewhat as the luminance of IF is below (or slightly above in particular case) TF. That is, when the luminance of IF is lower (or slightly higher) than that of $\mathrm{TF}$, the brightness of TF is somewhat enhanced. Although the initial enhancement in apparent brightness is slight, it appears consistently in almost all cases. The apparent brightness of TF begins to decrease as the luminance of IF is nearly equal to (or exceeds) that of TF. The rate of decrement increases as the luminance of IF increases.

Some differences are found among these curves, depending upon the different level of the test-field luminance. The position of the initial enhancement found in each curve moves towards higher luminance along the inducing-field axis as the testfield luminance increases. The position of the break seen in each curve moves towards higher luminance along the inducing-field luminance axis as the test-field luminance increases.

When the test-field luminance is at a fixed level, it seems to be dependent upon the area of IF where the position of enhancement or break appears. In order to de-

TABLE 2

Apparent brightness of the test field $(\mathrm{Bm}$, in $\log \mathrm{mL})$ under different test luminances $(\mathrm{Bt}$, in $\log \mathrm{mL}$ ), for different inducing luminances ( $\mathrm{Bi}$, in $\log \mathrm{mL}$ ), inducing diameters (in visual angle), and subjects.

\begin{tabular}{|c|c|c|c|c|c|c|c|c|c|}
\hline \multirow{2}{*}{$\underset{(\log \mathrm{mL})}{\mathrm{Bt}}$} & \multirow{2}{*}{$\begin{array}{l}\text { Diameter } \\
\text { of IF }\end{array}$} & \multirow{2}{*}{$S s$} & \multirow{2}{*}{$\begin{array}{l}\text { without } \\
\text { IF }\end{array}$} & \multicolumn{6}{|c|}{$\mathrm{Bi}$} \\
\hline & & & & -1.0 & -0.5 & 0 & 0.5 & 0.8 & 1.2 \\
\hline \multirow{4}{*}{1.0} & $0.8^{\circ}$ & $\begin{array}{l}\mathrm{YU} \\
\mathrm{ST}\end{array}$ & $\begin{array}{l}0.93 \\
0.89\end{array}$ & $\begin{array}{l}0.96 \\
0.90\end{array}$ & $\begin{array}{l}0.96 \\
0.87\end{array}$ & $\begin{array}{l}1.00 \\
0.88\end{array}$ & $\begin{array}{l}0.99 \\
0.91\end{array}$ & $\begin{array}{l}1.04 \\
0.89\end{array}$ & $\begin{array}{l}0.60 \\
0.46\end{array}$ \\
\hline & $1.0^{\circ}$ & $\begin{array}{l}\text { YU } \\
\text { ST }\end{array}$ & $\begin{array}{l}1.04 \\
0.91\end{array}$ & $\begin{array}{l}1.06 \\
0.90\end{array}$ & $\begin{array}{l}1.06 \\
0.91\end{array}$ & $\begin{array}{l}1.09 \\
0.90\end{array}$ & $\begin{array}{l}1.11 \\
0.95\end{array}$ & $\begin{array}{l}1.17 \\
0.84\end{array}$ & $\begin{array}{l}0.67 \\
0.26\end{array}$ \\
\hline & $2.0^{\circ}$ & $\begin{array}{l}\text { YU } \\
\text { ST }\end{array}$ & $\begin{array}{l}1.03 \\
0.92\end{array}$ & $\begin{array}{l}1.03 \\
0.96\end{array}$ & $\begin{array}{l}1.05 \\
0.93\end{array}$ & $\begin{array}{l}1.07 \\
0.98\end{array}$ & $\begin{array}{l}1.08 \\
1.02\end{array}$ & $\begin{array}{l}0.80 \\
0.95\end{array}$ & $\begin{array}{r}-0.08 \\
0.00\end{array}$ \\
\hline & & & & -1.0 & -0.5 & 0 & 0.2 & 0.4 & 0.7 \\
\hline \multirow{4}{*}{0.5} & $0.8^{\circ}$ & $\begin{array}{l}\text { YU } \\
\text { ST }\end{array}$ & $\begin{array}{l}0.53 \\
0.52\end{array}$ & $\begin{array}{l}0.53 \\
0.51\end{array}$ & $\begin{array}{l}0.53 \\
0.53\end{array}$ & $\begin{array}{l}0.62 \\
0.59\end{array}$ & $\begin{array}{l}0.64 \\
0.63\end{array}$ & $\begin{array}{l}0.55 \\
0.52\end{array}$ & $\begin{array}{l}0.28 \\
0.34\end{array}$ \\
\hline & $1.0^{\circ}$ & $\begin{array}{l}\text { YU } \\
\text { ST }\end{array}$ & $\begin{array}{l}0.51 \\
0.45\end{array}$ & $\begin{array}{l}0.53 \\
0.44\end{array}$ & $\begin{array}{l}0.54 \\
0.45\end{array}$ & $\begin{array}{l}0.57 \\
0.55\end{array}$ & $\begin{array}{l}0.64 \\
0.62\end{array}$ & $\begin{array}{l}0.64 \\
0.43\end{array}$ & $\begin{array}{l}0.28 \\
0.18\end{array}$ \\
\hline & \multirow[t]{2}{*}{$2.0^{\circ}$} & $\begin{array}{l}\text { YU } \\
\text { ST }\end{array}$ & $\begin{array}{l}0.60 \\
0.48 \\
\end{array}$ & $\begin{array}{l}0.61 \\
0.48 \\
\end{array}$ & $\begin{array}{l}0.65 \\
0.71 \\
\end{array}$ & $\begin{array}{l}0.77 \\
0.78 \\
\end{array}$ & $\begin{array}{l}0.78 \\
0.57\end{array}$ & $\begin{array}{l}0.38 \\
0.10\end{array}$ & $\begin{array}{l}-0.51 \\
-0.84\end{array}$ \\
\hline & & & & $-1,0$ & -0.7 & -0.5 & -0.3 & -0.1 & 0.2 \\
\hline \multirow{4}{*}{0} & $0.8^{\circ}$ & $\begin{array}{l}\mathrm{YU} \\
\mathrm{ST}\end{array}$ & $\begin{array}{l}0.04 \\
0.04\end{array}$ & $\begin{array}{l}0.06 \\
0.06\end{array}$ & $\begin{array}{l}0.06 \\
0.04\end{array}$ & $\begin{array}{l}0.06 \\
0.05\end{array}$ & $\begin{array}{l}0.08 \\
0.20\end{array}$ & $\begin{array}{l}0.02 \\
0.19\end{array}$ & $\begin{array}{r}-0.28 \\
-0.38\end{array}$ \\
\hline & $1.0^{\circ}$ & $\begin{array}{l}\text { YU } \\
\text { ST }\end{array}$ & $\begin{array}{r}0.07 \\
-0.03\end{array}$ & $\begin{array}{r}0.05 \\
-0.05\end{array}$ & $\begin{array}{r}0.10 \\
-0.04\end{array}$ & $\begin{array}{l}0.12 \\
0.02\end{array}$ & $\begin{array}{l}0.24 \\
0.16\end{array}$ & $\begin{array}{l}0.23 \\
0.03\end{array}$ & $\begin{array}{l}-0.40 \\
-0.27\end{array}$ \\
\hline & \multirow[t]{2}{*}{$2.0^{\circ}$} & $\begin{array}{l}\mathrm{YU} \\
\mathrm{ST}\end{array}$ & $\begin{array}{l}0.10 \\
0.10\end{array}$ & $\begin{array}{l}0.08 \\
0.11\end{array}$ & $\begin{array}{l}0.07 \\
0.12\end{array}$ & $\begin{array}{l}0.19 \\
0.23\end{array}$ & $\begin{array}{l}0.15 \\
0.21\end{array}$ & $\begin{array}{l}0.11 \\
0.02\end{array}$ & $\begin{array}{l}-0.54 \\
-0.70\end{array}$ \\
\hline & & & & -1.0 & -0.8 & -0.7 & -0.6 & -0.4 & -0.3 \\
\hline \multirow{3}{*}{-0.5} & $0.8^{\circ}$ & $\begin{array}{l}\text { YU } \\
\text { ST }\end{array}$ & $\begin{array}{l}-0.53 \\
-0.49\end{array}$ & $\begin{array}{l}-0.52 \\
-0.48\end{array}$ & $\begin{array}{l}-0.50 \\
-0.48\end{array}$ & $\begin{array}{l}-0.50 \\
-0.47\end{array}$ & $\begin{array}{l}-0.45 \\
-0.46\end{array}$ & $\begin{array}{r}-0.45 \\
-0.33\end{array}$ & $\begin{array}{l}-0.62 \\
-0.57\end{array}$ \\
\hline & $1.0^{\circ}$ & $\begin{array}{l}\text { YU } \\
\text { ST }\end{array}$ & $\begin{array}{l}-0.48 \\
-0.61\end{array}$ & $\begin{array}{l}-0.49 \\
-0.59\end{array}$ & $\begin{array}{l}-0.48 \\
-0.58\end{array}$ & $\begin{array}{l}-0.47 \\
-0.45\end{array}$ & $\begin{array}{l}-0.40 \\
-0.40\end{array}$ & $\begin{array}{l}-0.47 \\
-0.59\end{array}$ & $\begin{array}{l}-0.75 \\
-0.70\end{array}$ \\
\hline & $2.0^{\circ}$ & $\begin{array}{l}\mathrm{YU} \\
\mathrm{ST}\end{array}$ & $\begin{array}{l}-0.51 \\
-0.54\end{array}$ & $\begin{array}{l}-0.51 \\
-0.55\end{array}$ & $\begin{array}{l}-0.49 \\
-0.54\end{array}$ & $\begin{array}{l}-0.51 \\
-0.55\end{array}$ & $\begin{array}{l}-0.37 \\
-0.59\end{array}$ & $\begin{array}{l}-0.58 \\
-0.87\end{array}$ & $\begin{array}{l}-1.09 \\
-1.26\end{array}$ \\
\hline
\end{tabular}




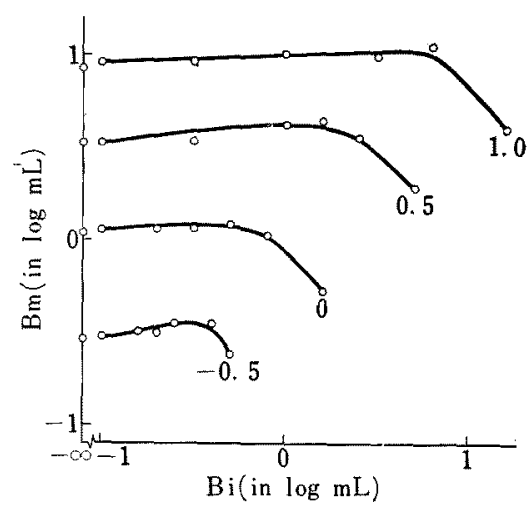

Fig. 3A, (a)

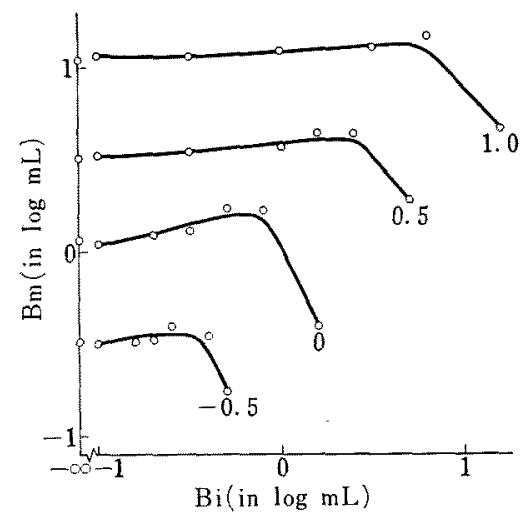

FIG. 3A, (b)

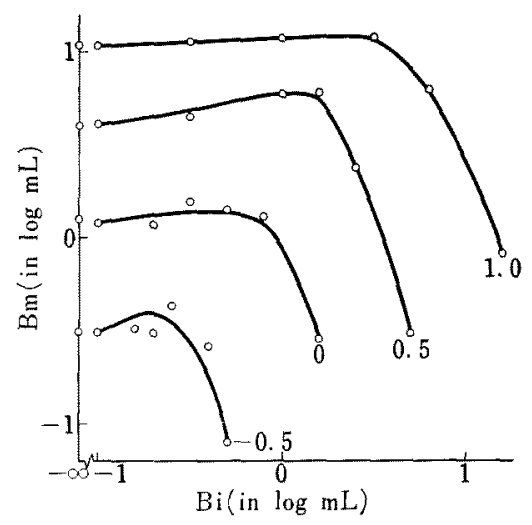

FIG. 3A, (c)

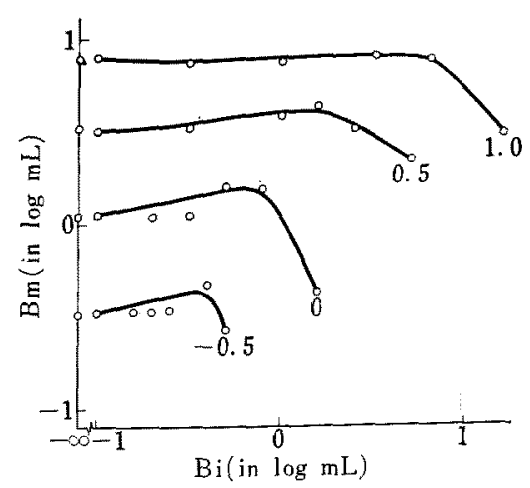

FIG. 3B, (a)

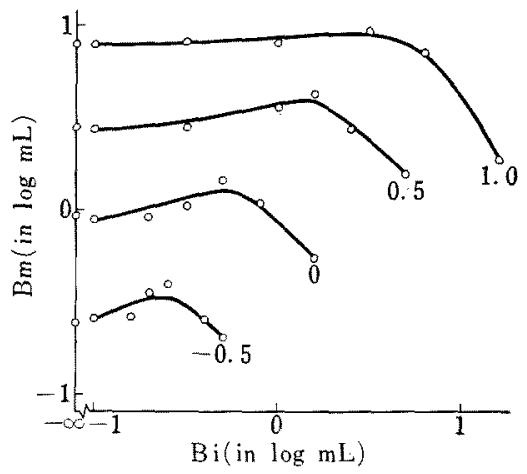

Fig. 3B, (b)

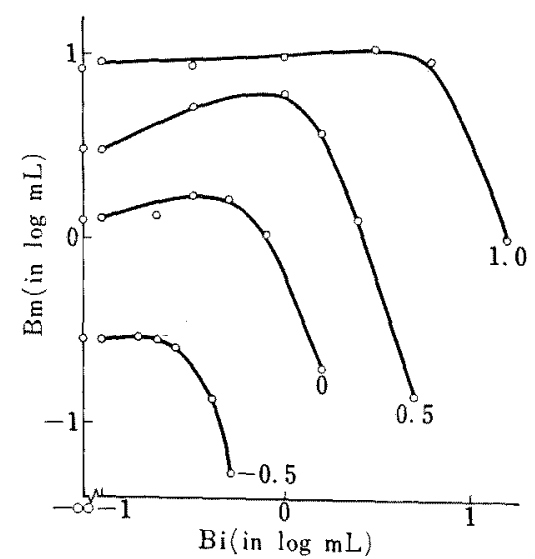

FIG. 3B, (c)

FIG. 3. Apparent brightness of the test field $(\mathrm{Bm}$, in $\log \mathrm{mL})$ plotted against the inducingfield luminance $(\mathrm{Bi}$, in $\log \mathrm{mL})$. The parameters on the curves are the test-field luminances (Bt, in $\log \mathrm{mL}$ ). Fig. $3 \mathrm{~A}$ and $3 \mathrm{~B}$ are for subject $\mathrm{YU}$ and for subject $\mathrm{ST}$, respectively; (a) for $0.8^{\circ}$, (b) for $1.0^{\circ}$, and (c) for $2.0^{\circ}$ of arc diameter of the inducing field. 
monstrate the relationship between the position of enhancement or break and the inducing-field areas, the results were calculated in a somewhat different way, i.e., $\log B d$ was calculated by the equation $\log$ $B d=\log B m-\log B o$, where $B o$ represents the matched luminance from the control session. Thus, $\log B d$ is plotted against $\log B i$ in Fig. $4 \mathrm{~A}$ and $4 \mathrm{~B}$, in which three different curves are shown, corresponding to each of the three areas of the inducing field. Fig. 4A and 4B contain four sets of these three curves together, one set for each of the four luminance levels of the test field, where each of four sets is separated arbitrary along the ordinate axis to avoid overlap. Curves were fitted to the points by inspection.

The position of the initial enhancement tends to move somewhat towards the lower luminance along the inducing-field luminance axis as the inducing-field area increases. This tendency is seen clearly, when the test-field luminance is $-0.5 \log \mathrm{mL}$ (for subject $\mathrm{YU}$ ), or $-0.5,0$, and $0.5 \mathrm{log}$ $\mathrm{mL}$ (for subject ST). The position of the break also seems to show the same tendency as that of the enhancement. As can be seen in Fig. 4A and $4 \mathrm{~B}$, the position of the break (it will be convenient to define it here as that where the curves intersect the line $\log B d=0$ ) tends to move towards lower luminance along the inducing-field luminance axis as the inducing-field area increases, except the case where the testfield luminance is $1.0 \log \mathrm{mL}$ in Fig. 4B.

Moreover, it should be noted that the rate of decrease in the test-field brightness is more steep as the area of the inducing field increases. These tendencies are observed in almost all curves.

\section{Discussion}

According to the results obtained here, when the inducing luminance is much lower than the test-field luminance, the apparent brightness shows little difference from that without the inducing field. As the luminance of the inducing field increases from zero to some extent, however, the test-field brightness is raised somewhat. As the inducing luminance reaches, or exceeds, the luminance of test field, it begins to decrease. That is, two kinds of effect upon TF are observed here; one of them may be an enhancement and the latter a depression. Therefore, the results seem to be in general

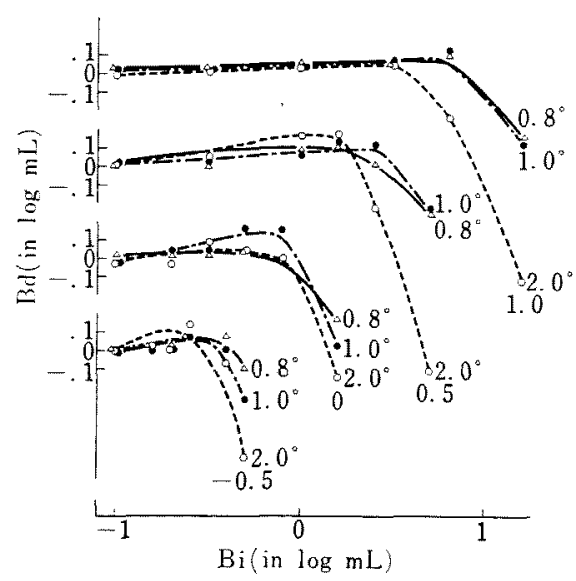

Fic. 4A

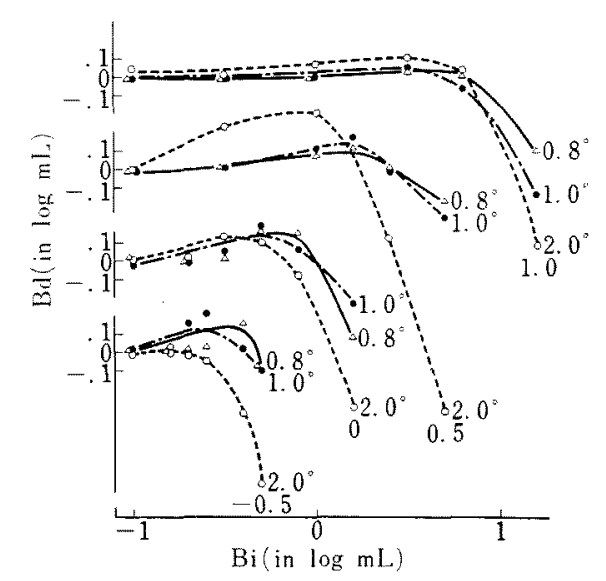

FIg. $4 \mathrm{~B}$

Fig. 4. Bd plotted against the inducing-field luminance (Bi). The parameters on the curves are the test-field luminances (Bt, in $\log \mathrm{mL}$ ) and the inducing-field diameters (in visual angle). Fig. $4 \mathrm{~A}$ and $4 \mathrm{~B}$ are for subject $\mathrm{YU}$ and for subject ST, respectively. 
agreement with those of Heinemann's (1955).

Whereas the general results obtained concerning a depression are in agreement with those of Hess and Pretori (1894), Diamond (1953), Fry and Alpern (1953), and Leibowitz et al. (1953), the results obtained concerning an initial enhancement differ from those of the investigators just cited. It should be noted here that while in these investigations rectangles were used as inducing- and test-fields, in MacLeod's (1947) and Heinemann's (1955) experiments the test fields used were surrounded by the contiguous inducing field.

Recently, Diamond (1960) has presented two possible ways in which enhancement can be produced; one of them is to increase the area of the inducing field so that it is many times the size of the test field. Indeed, since the outer diameter of the inducing field is $55^{\prime}$ and that of test field is $28^{\prime}$ in Heinemann's experiment, the area of the former is about three times larger than that of the latter. But it should be noted that in the present experiment the area of the inducing field is smaller than that of the test field when the outer diameter of the former is $0.8^{\circ} .3$ In order to produce enhancement, therefore, it would not be necessary to increase the inducing area many times larger than the test area as long as at least the test field is surrounded completely by the contiguous inducing field.

Moreover, Diamond has presented a prediction that the enhancement effect decreases as the test-field luminance increases. This prediction seems to be supported by the results shown in Fig. 4A and 4B. That is to say, the curves of $1.0 \mathrm{log}$ $\mathrm{mL}$ test-field luminance show the smallest

${ }^{3}$ Now let the radii of test- and inducing-fields be $a$ and $(a+b)$, respectively, and let the areas of both fields be $S_{1}$ and $S_{2}$, respectively, then $S_{1}=\pi a^{2}$ and $S_{2}=\pi b(2 a+b)$. When the outer diameters of the inducing- and test-ficlds arc $0.8^{\circ}$ and $0.6^{\circ}$, respectively, $a=3 b$. Hence, $S_{1}=9 \pi b^{2}$, and $S_{2}=7 \pi b^{2}$. From this, $S_{1}>S_{2}$. enhancement effect. The decrease in enhancement with increased test luminance is also seen in Heinemann's data, though there are some discrepancies between Diamond's theoretical curves and Heinemann's data. The curves obtained here are more similar to those of Heinemann's experiment, than to those based on Diamond's theoretical prediction.

The position of the enhancement or that of the break, of course, cannot be regarded as conclusively established until their position has been measured with greater precision. Nonetheless, it should be noted that in the present results the position of the enhancement and that of the break vary as the inducing-field area varies. Also in Diamond's results (1953), and in Heinemann's results (1955), it is seen that depression begins to occur before the inducing luminance reaches the same level of the test luminance. The results obtained here show that, when the area of the inducing field is $0.8^{\circ}$ or $1.0,^{\circ}$ depression begins to occur approximately at the point at which inducing luminance equals or exceeds test luminance. However, when the inducing area is $2^{\circ}$, depression begins to occur at the point where the inducing-field luminance is less than that of the test field. This is seen more clearly as the test luminance increases. If this is the case, it should be observed that the apparent brightness of the test field surrounded by an inducing field of equal luminance varies as the inducing-field area increases. That is, if depression begins to occur at the point where inducing luminance exceeds test luminance, the test field surrounded by the equal luminance field should appear brighter than when isolated. And if depression begins to occur at the point at which inducing luminance is less than the test luminance, the test field surrounded by the equal luminance should appear darker than when isolated. On the other hand, if depression begins to occur always at the point where inducing luminance approximately equals test luminance, the 
test-field brightness should be kept nearly constant, in the case where the test field is surrounded by equal luminance, irrespective of differences in the inducing-field area. In our Experiment I, however, the condition in which the inducing- and testfields were of equal luminance was not included. Experiment II was designed to examine whether the apparent brightness of the test field surrounded by an inducing field of equal luminance varies as the inducing area increases.

\section{EXPERINEXT II}

\section{Method}

This experiment was designed to measure the apparent brightness of the test field surrounded by an inducing field of equal luminance. Four different levels of inducing- and test-field luminance ranging from -0.5 to $1.0 \log \mathrm{mL}$ were used. For each inducing- and test-field luminance, the following five different inducingfield areas were prepared : $0.8^{\circ}, 1.0^{\circ}, 1.2^{\circ}, 1.5^{\circ}$, and $2.0^{\circ}$. One experimental session consisted of five levels of inducing-field area at each of the inducing- and test-field luminances. The order of presenting different areas was balanced for two subjects. The order of presenting the inducing- and test-field luminances was balanced for two subjects. Other procedures were the same as those for Experiment I.

Results

The individual results of the two $S$ s are presented in Table 3. The $\log B m$ is plotted against the diameter of the inducing field (in visual angle) in Fig. $5 \mathrm{~A}$ and $5 \mathrm{~B}$; the former for subject $\mathrm{YC}$ and the latter for subject ST. The data from the control session are plotted at the point at which the diameter is $0.6^{\circ}$. The apparent brightness of the test field decreases gradually as the area of the inducing field increases as can be seen in Fig. $5 \mathrm{~A}$ and $5 \mathrm{~B}$. Moreover, for both subjects, it can be seen that the rate of changes in $B m$ is more steep as the inducing- and test-luminances increase.

\section{Discussion}

These findings are consistent with the results obtained in Experiment I. That is to say, these findings show that at larger areas of the inducing field, depression begins

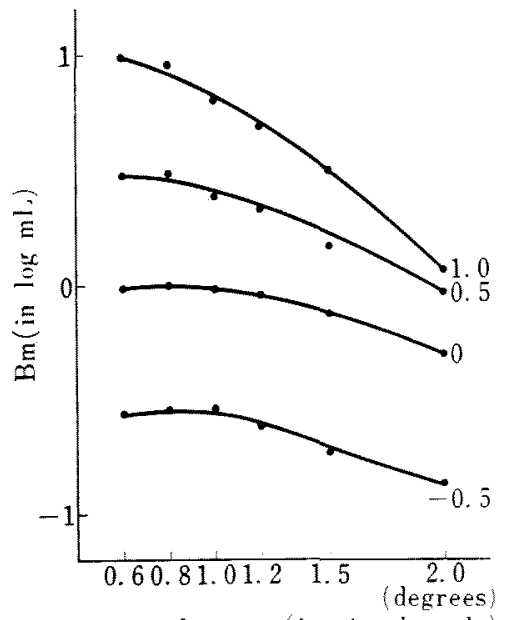

Inducing diameter (in visual angle)

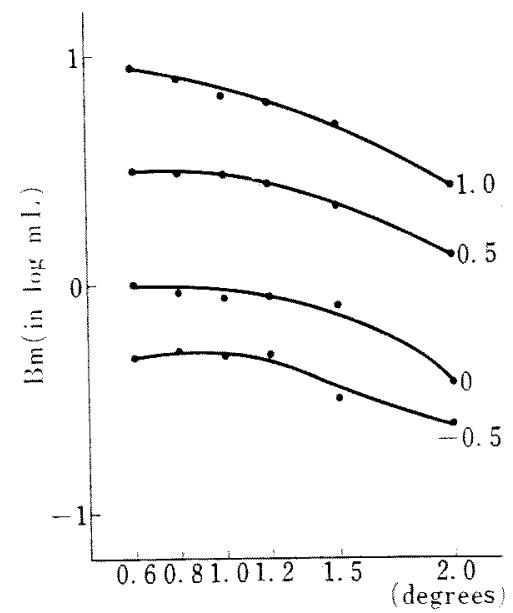

Inducing diameter (in risual angle) FIG. 5B

FIG. 5. Apparent brightness of the test field $(\mathrm{Bm}$, in $\log \mathrm{mL})$ plotted against the inducing field diameter (in visual angle). The parameters on the curves are the test-field luminances (Bt, in $\log \mathrm{mL}$ ). Fig. $5 . \mathrm{A}$ and $5 \mathrm{~B}$ are for subject $\mathrm{IL}$ and for subject $\mathrm{ST}$, respectively. 
TABLE 3

Apparent brightness of the test field ( $\mathrm{Bm}$, in $\log \mathrm{mL}$ ) under different inducing- and test-luminances $(\mathrm{Bi}, \mathrm{Bt}$ in $\log \mathrm{mL}$ ), for different inducing diameters (visual angle) and subjects.

\begin{tabular}{rlrrrrrr}
\hline \multirow{3}{*}{$\mathrm{Bt}=\mathrm{Bi}$} & Ss & $\begin{array}{c}\text { without } \\
\text { IF }\end{array}$ & \multicolumn{6}{c}{ Diameter of IF } \\
& & & $0.8^{\circ}$ & $1.0^{\circ}$ & $1.2^{\circ}$ & $1.5^{\circ}$ & \multicolumn{1}{c}{$2.0^{\circ}$} \\
\hline \multirow{2}{*}{1.0} & YU & 0.99 & 0.96 & 0.80 & 0.69 & 0.50 & 0.06 \\
& $\mathrm{ST}$ & 0.95 & 0.90 & 0.82 & 0.79 & 0.69 & 0.42 \\
0.5 & YU & 0.48 & 0.48 & 0.39 & 0.33 & 0.17 & -0.03 \\
& ST & 0.50 & 0.49 & 0.48 & 0.44 & 0.34 & 0.12 \\
0 & YU & -0.01 & 0.00 & -0.01 & -0.04 & -0.12 & -0.30 \\
& ST & 0.00 & -0.03 & -0.06 & -0.05 & -0.10 & -0.44 \\
& YU & -0.56 & -0.55 & -0.54 & -0.61 & -0.73 & -0.86 \\
& ST & -0.32 & -0.28 & -0.31 & -0.31 & -0.50 & -0.62
\end{tabular}

to occur at the point where the inducing luminance is less than the test luminance.

Corresponding results to those obtained here were found in Heinemann's experiment (1955) in which the inducing annulus was equal in luminance to the test field. Therefore, when the subject was, in effect viewing a circle approximately twice the size of the test circle, the brightness of the test circle diminished. This drop in brightness seems to occur more noticeably at higher luminances, for seven different levels of luminance used by him ranging from -1.45 to $1.55 \log \mathrm{mL}$. This drop in brightness was found to occur also in Diamond's study (1953). In his experiment, this phenomenon was noted at all levels of the test-field luminance ranging from -0.39 to $2.71 \log \mathrm{mL}$.

Experiment I showed that when the lower test luminances were surrounded by the relatively small inducing field, depression began to occur at the point where inducing luminance somewhat exceeded test luminance. In the present experiment also, at the lower luminances of the test field $(0.5$ and $0 \log \mathrm{mL})$, the apparent brightness of the test field shows the tendency to be brighter than when isolated. But this increase in brightness is too slight to be concluded that it does occur.

On the other hand, the drop in brightness suggests that the apparent brightness of a field might diminish as its area in- creases. Because, when the inducing- and test-fields are of equal luminance, the subject would view a uniform field with area corresponding to the sum of inducingand test-area, not the test field surrounded by the inducing field.

Hanes (1951) investigated the relationship between apparent brightness and area more directly. Five different circular areas, ranging from $9^{\prime}$ to $2^{\circ} 24^{\prime}$ of visual angle, were explored at four different luminance levels, ranging from 0.1 to 100.0 $\mathrm{mL}$. Hanes found that at lower luminances $(0.1$ and $1.0 \mathrm{~mL})$ the apparent brightness increased significantly with increasing area, and this increase leveled off for the larger areas. At the highest luminance $(100.0 \mathrm{~mL})$, however, the apparent brightness decreased significantly with increasing area.

Diamond (1962) reexamined whether apparent brightness of a field could be changed by varying its area. While in Hanes' study, both standard and comparison fields were presented simultaneously to both eyes, in Diamond's experiment the binocular matching method was used. The test-field radius was varied in six steps from $2.69^{\prime}$ to $26.86^{\prime}$, for any one of six levels of match-field luminances from threshold to $2.56 \log \mathrm{mL}$. He found that only at threshold were there systematic differences in test luminance as a function of test area. Threshold luminance de- 
creased as area increased. For suprathrsheold match luminances, however, test luminance remained relatively constant as test area increased. Changes of test luminance that occured were no greater than those attributable to chance variation. Diamond attempted to account for these results by a theory based upon possible inhibitory interaction in the retina. Curves generated by his theory were fitted to the data.

In spite of Diamond's efforts, the drop in brightness with increased area has not been accounted yet. Data presented by Diamond in 1953, as well as Heinemann's and ours, are inconsistent with those obtained by Diamond in 1962. However, it should be noted here that even when the inducing- and test-fields were of equal luminance, the inducing- and test-fields were separated by a very thin black line. Under such circumstances, any slight differences between the luminances of the inducing- and test-fields, based on the difference between Path 1 and Path 2 in optical system used here, make it difficult to see the both fields as uniform. Such being the case, it is impossible to form a conclusion concerning the brightness-area relationship from the results obtained in Experiment II where the inducing- and test-luminances, as based on the density scale, were of equal value. Therefore, Experiment III was planned to examine whether the apparent brightness of a field is to be determined by its area.

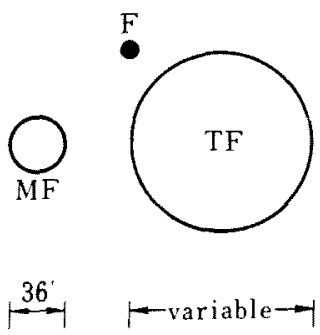

Fig. 6. Stimulus pattern used in Exp. III. Binocular views with fixation points fused into one point $F$.

\section{EXPERTMENT III}

Method

The design of the present experiment was different from those in Experiment I and II with respect to the following points: (a) The test field was presented to the $S$ 's right eye and the matching field was presented to the $S$ 's left eye, and (b) no inducing field was presented. The stimulus patterns used here are those shown in Fig. 6, in which only the binocular view is presented.

Thus, in the present experiment, the test-field luminance necessary to match the brightness of a constant matching-field luminance was explored as a function of six test-field areas, ranging from $0.6^{\circ}$ to $2.0^{\circ}$, and for four different levels of test luminance ranging from -0.5 to $1.0 \log \mathrm{mL}$. An experimental session per day was designed to explore six test-field areas, at a fixed test-field luminance. The order of presenting different area was randomized. Test-field luminances were presented in random sequence for each subject. Other procedures were the same as those for Experiment II.

Results

The individual results for subject YU and subject ST are presented in Table 4 and are depicted in Fig. $7 \mathrm{~A}$ and $7 \mathrm{~B}$, in which the apparent brightness of the test field is plotted against the test-field area (in visual angle). As shown in Fig. $7 \mathrm{~A}$ and $7 \mathrm{~B}, \log B m$ decreases gradually as the test-field area increases at the higher testfield luminances. But the change of $\log$ $\mathrm{Bm}$ with the increase of test areas at the lower test luminances is not a monotonically decreasing function. That is, the brightness of the test field increases up to $0.8^{\circ}$ or $1.0^{\circ}$, but it then decreases gradually. In particular, the increase in brightness is seen clearly at the lowest test luminance in Fig. 7A. However, a very slight increase is seen in the case of subject ST.

Discussion

It should be noted here that there are differences between the results of Experiments II and III. The increase in apparent brightness in the present result is more 


\section{TABLE 4}

Apparent brightness of the test field $(\mathrm{Bm}$, in $\log \mathrm{mL})$ under different test luminances

(Bt, in $\log \mathrm{mL}$ ), for different test diameters (in visual angle) and subjects.

\begin{tabular}{ccrrrrrr}
\hline Bt & Ss & \multicolumn{7}{c}{ Diameter of IF } \\
& & $0.6^{\circ}$ & $0.8^{\circ}$ & $1.0^{\circ}$ & $1.2^{\circ}$ & $1.5^{\circ}$ & $2.0^{\circ}$ \\
\hline \multirow{2}{*}{1.0} & YU & 1.00 & 1.00 & 0.90 & 0.93 & 0.87 & 0.67 \\
& ST & 1.11 & 1.11 & 1.06 & 1.05 & 0.99 & 0.71 \\
\multirow{2}{*}{0.5} & YU & 0.50 & 0.53 & 0.44 & 0.45 & 0.39 & 0.37 \\
& ST & 0.58 & 0.53 & 0.55 & 0.51 & 0.47 & 0.39 \\
& YU & 0.00 & 0.03 & -0.04 & -0.02 & -0.07 & -0.18 \\
& ST & 0.06 & 0.09 & 0.06 & 0.08 & -0.01 & -0.34 \\
& YU & -0.56 & -0.39 & -0.47 & -0.50 & -0.59 & -0.65 \\
& ST & -0.30 & -0.27 & -0.27 & -0.35 & -0.35 & -0.49
\end{tabular}

clear, at least in the case of subject YU. The rate of decrease in brightness with the increase of test area is slower than in Experiment II. These may be due to the differences in both experiments in that the inducing- and test-fields in Experiment II are separated by a thin black line. The subject reported that it was difficult to see the inducing- and test-fields as an evenly illuminated field in Experiment II.

The results obtained in the present and former experiments seem, except for slight

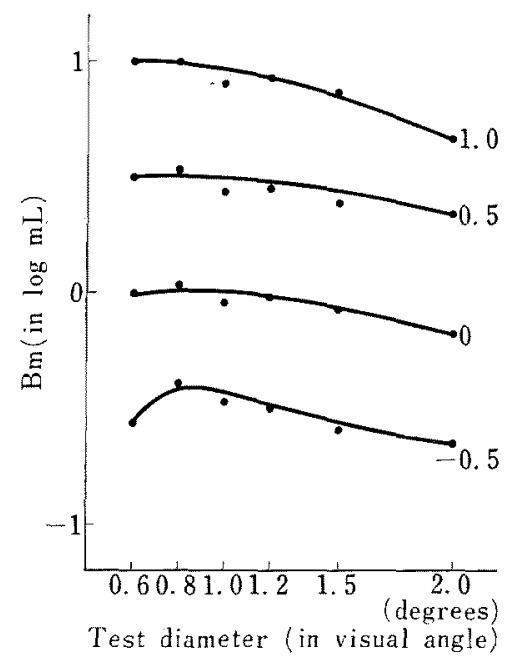
Fic, 7A

Fic.

differences, to confirm the tendencies obtained in Experiment $I$ in which the break moves towards the higher luminances along the inducing luminance axis as the inducing area increases. Especially, YU's results observed in Experiment III seem to support those of Experiment $I$ in which at the lower test luminances apparent brightness is higher than that without the inducing field, when it is surrounded by the relatively small field of almost equal luminance.

It is worthwhile to note that the present

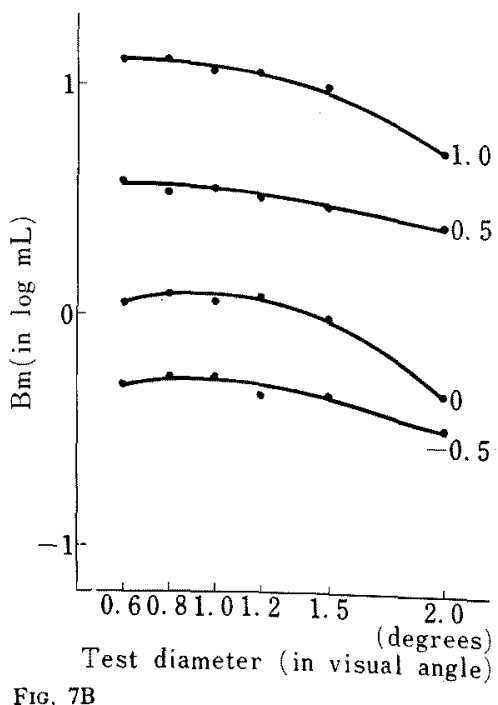

FIG. 7. Apparent brightness of the test field $(\mathrm{Bm}$, in $\log \mathrm{mL})$ plotted against the test-field diameter (in visual angle) for different test-luminance levels. Fig. 7A and 7B are for subject YU and for subject ST, respectively. 
results differ from those obtained by Diamond, even though slight inconsistencies are found between results in Experiment $I$ and II. There are three possible sources for the disagreement between Diamond's data and ours: First of all, the ranges of luminances adiffer. The matuminances used by Diamond rangefrom 0.188 to $2.56 \log \mathrm{mL}$, while in the present experiments range from -0.5 to $1.0 \log \mathrm{mL}$.

The second difference lies in the difference of test field area. The radii of the test fields range from $2.69^{\prime}$ to $26.86^{\prime}$ in Diamond's experiment, while in the present experiment the test-field raddii range from $18^{\prime}$ to $60^{\prime}$. Moreover, Diamond used a match field of $13.5^{\prime}$ in radius, while we used $18^{\prime}$ matching field. Therefore, only the latter halves of his curves are comparable with the former halves of ours in Fig. 7A and 7B. Our results also show that the test brightness remains approximately constant, as far as the test areas range from $0.6^{\circ}$ to $1.2^{\circ}$ (their radii ranging from $18^{\prime}$ to $36^{\prime}$ ), except the case in which the test luminance is $-0.5 \log \mathrm{mL}$. It may be concluded, therefore, that the disagreement between Diamond's results and ours can be ascribed to the difference in test areas employed in each experiment.

The third difference lies in the distance separating the test- and matching-fields. The visual angle between centers of two fields is $86^{\prime}$ in Diamond's experiment, while the angular separation between the centers is $120^{\prime}$ in the present experiment. Therefore, in Diamond's experiment, the angular separation between the edges of the inducing- and test-fields varies from $69.81^{\prime}$ to $45.64^{\prime}$ as the test area varies from $2.69^{\prime}$ to $26.86^{\prime}$ in radius, while in the present experiment, the angular separation varies from $84^{\prime}$ to $42^{\prime}$ as the test area varies from $18^{\prime}$ to $60^{\prime}$ in radius.

It is known that interaction effects in one eye are a function of the distance between the interacting stimuli; the greater the distance, the less the interaction (Beitel, 1936; Fry and Alpern, 1953). In addi- tion, according to Diamond (1953), the binocular interaction effects are also a function of the retinal disparities that separate the stimulations in the two eyes from corresponding points; the greater the disparity, and the greater the apparent separation, the less the interaction. In Diamond's experiment, in which separations between the match field and the inducing- and test-fields were $42^{\prime}, 70^{\prime}$, and $119^{\prime}$, it was found that, as the separation increased, the apparent brightness of the test field showed a slight decrease over the entire range of inducing-field luminances.

If such a binocular interaction effect does exist, and if the effect is a function of the retinal disparities, it may be concluded that the variation_of visual angle between the and test-fields in our Experiment III, ranging from $84^{\prime}$ to $42^{\prime}$, causes the difference in binocular interaftions between the matching- and fields. It may be said that the disagreement between both experiments can partly be ascribed to the difference in the range of distance between the interacting stimuli.

Further experimentation will make it possible to conclude which one of the possibilities mentioned above is more likely. Nevertheless, an increase in the test brightness, which is observed at its lower luminances in Fig. 7A, is not consistent with a prediction presented by Diamond (1960). Since, according to his theory, a test-field brightness at suprathreshold luminance would remain essentially constant irrespective of increased area, there remains a problem of how to interpret such an increase in brightness as observed in the present experiment.

\section{Summary}

The present study was designed to examine whether the apparent brightness of the test field was affected by varying the inducing-field luminance and area, by using a binocular matching method. The test field was disc-shaped and, in Exp. I and II, was surrounded by a contiguous 
annular inducing field.

Effects of inducing-luminance and area upon the test brightness were studied in Exp. I. The main results were as follows: (1) As the luminance of the inducing field increased from zero to some extent, the test field brightness was slightly enhanced. As the inducing luminance reached, or exceeded, the test luminance, the test brightness began to be depressed. (2) The position of the enhancement showed a tendency to move towards the lower luminance along the inducing-field luminance axis as the inducing area increased. (3) As the inducing area increased, depression began to occur at the point where the inducing luminance was less than the test luminance.

Exp. II was designed to examine whether the test brightness surrounded by the inducing field of equal luminance could be affected by varying area of the inducing field. Apparent test brightness was found to decrease gradually with increasing area.

Exp. III was designed to examine whether the apparent brightness of a field could be changed by varying its area. At the higher test luminances, the apparent brightness was found to decrease gradually with increasing area. At the lowest test luminance, on the other hand, a slight increase in brightness was observed.

The results of Exp. II and III, except slight differences between them, were found to be consistent with those of Exp. I. Possible sources for the disagreement between the previous investigators and ours were briefly discussed.

\section{REFERENCES}

Beitel, R.J. 1936 Inhibition of threshold excitation in the human eye. 7. gen. Psychol., 14, 31-61.

Diamond, A. L. 1953 Foveal simultaneous brightness contrast as a function of inducing- and test-field luminances. $\mathcal{J}$.exp. Psychol., 45, 304 314.

DLAMond, A. L. 1955 Foveal simultaneous contrast as a function of inducing-field area. 7 . exp. Psychol., 50, 144-152.

Dramond, A. L. 1960 A theory of depression and enhancement in the brightness response. Psychol. Rev., 67, 168-199.

Dlamond, A. L. 1962 Brightness of a field as a function of its area. 7. opt. Soc. Amer., 52, 700-706.

Fry, G. A., \& ALPERN, M. 1953 The effect of a peripheral glare source upon the apparent brightness of an object. 7. opt. Soc. Amer, , 43, 189-195.

HANEs, R. M. 1951 Suprathreshold area brightness relationships. 7. opt. Soc. Amer., 41, 2831.

Heinemann, E. G. 1955 Simultaneous brightness induction as a function of inducing- and testfield luminances. 7. exp. Psychol., 50, 89-96.

Hess, C., \& Pretori, H. 1894 Messende Untersuchungen über die Gesetzmässigkeit des simultanen Helligkeitskontrastes. Graefes Arch. Ophth., 40, 1-24. (Heinemann, E. G. 1955 7. exp. Psychol., 50)

Leibowtrz, H., Mote, F. A., \& Thurlow, W. R. 1953 Simultaneous contrast as a function of separation between test and inducing fields. 7. exp. Psychol., 46, 453-456.

MACLEOD, R.B. 1947 The effects of artificial penumbrae on the brightness of included areas. Miscellanea Psychologica Albert Michotte. Louvain: Inst. Sup. Philos. (Heinemann, E.G. 1955 7. exp. Psychol., 50)

(Received Jun. 27, 1965) 